THE FRENCH TORPEDO CRUISER CONDOR. AMONG the ships that are at present anchored in the
roadstead of Barcelona, the Condor will certainly be The public will indeed be struck by the imposing spectacle offered by the French, Italian, and Austrian ironclads that have come to do honor to Spain, but these are of known types whose fighting qualities have
in a measure been tested. The attention of naval men is turned at present rather to ships of medium tonnage, designed to do battle with both torpedo boat and ships of heavy tonnage such as ironclads.

In order to fultill this double mission it required, in fact, manageable vessels having a speed analogous to that of torpedo boats and capabe of remaining at sea,
better than they, in a state to give or refuse battle, maneuvering easily, armed with torpedoes against ironclads, and with rapid-firing guns against torpedo boats, in a word, a sort of ship to do everything, despite it slight displacement.

It was of such an idea that was begotten, first, the Bombe, of 304 tons, and afterward the Condor, which 1,272 tons. We now have four specimens of this type, for the Epervier, which at present forms part of the Channel squadron, the Vautour and the Faucon, which are not yet entirely finished, are absolutely like the

These ships measure 223 feet in length and 29 in width amidship, and have in draught of 15 feet.
As for defensive power, the hull has an armored deck
THE SUPPORTING POWER OF SOILS. By RaNDell Hunt, Member of the Civil Engineer Read Apri 2,1888 .

IT is of ten necessary for the engineer to prescribe a limit of load, per unit of surface, in designing foun-
dations for structures resting upon soil. In the sence of the time and means to make actual tests of the soil, he must confine himself to an investigation of
existing successful structures upon a soil as nearl similar to the one under consideration as he can find. marks upon the actual supporting power of soils as deown observation and the reccrded matter from our have been accessible.

It is probably possible to devise a general mathepatical formula which would be applicable to the supporting power of any soil, but such an expression
would necessitate our knowing so many particulars as to the character of the soil, such as its weight and
natural slope, that we could judge of its actual strength fully as well without applying it. At any rate, we shall confine ourselves to-night simply to the The Supporting Power of Clay.-The supporting
practical side of the matter. power of clay is very variable and depends in a large measure upon the variety and upon its degree of saturation with moisture. In the roadbed of railroads,
when the "surfacing" has been done with clay, a
structed upon a concretefoundation. The pressure per much as a foot. The pressure per square foot of the
entire foundation of this bridge is 5 tons. When the new Westminster Bridge was built the load per pile was reduced to about 12 tons, while the load per square foot of the entire foundation was reduced
to 2 tons. I find no record of this bridge having shown any signs of settlement

rt Stevenson* attempted to load a stiff hard clay with 5 tons per square foot. He was building were completed serious settlements took place, and he
decreased the amount per foot by making his foundation of greater area than first determined upon. constructed another, at Newcastle-on-Tyne, with only $11 / 2$ tons per square foot of foundation, which was suc. cessful. Both these chimneys are described as being founded on hard, compact clay.

The subsoil of the vast valley of the Red River of the North is a bed of clay, which varies in depth from (1) to ish color, and appears more or less hard and firm in proportion to the amount of moisture contained in it. Che considered, it has a large amount of carbotreated with in it, as can be seen from its action when view in a place where and when freshly opened up to In 1881, at Fargo, Dakota, a brick building, of four

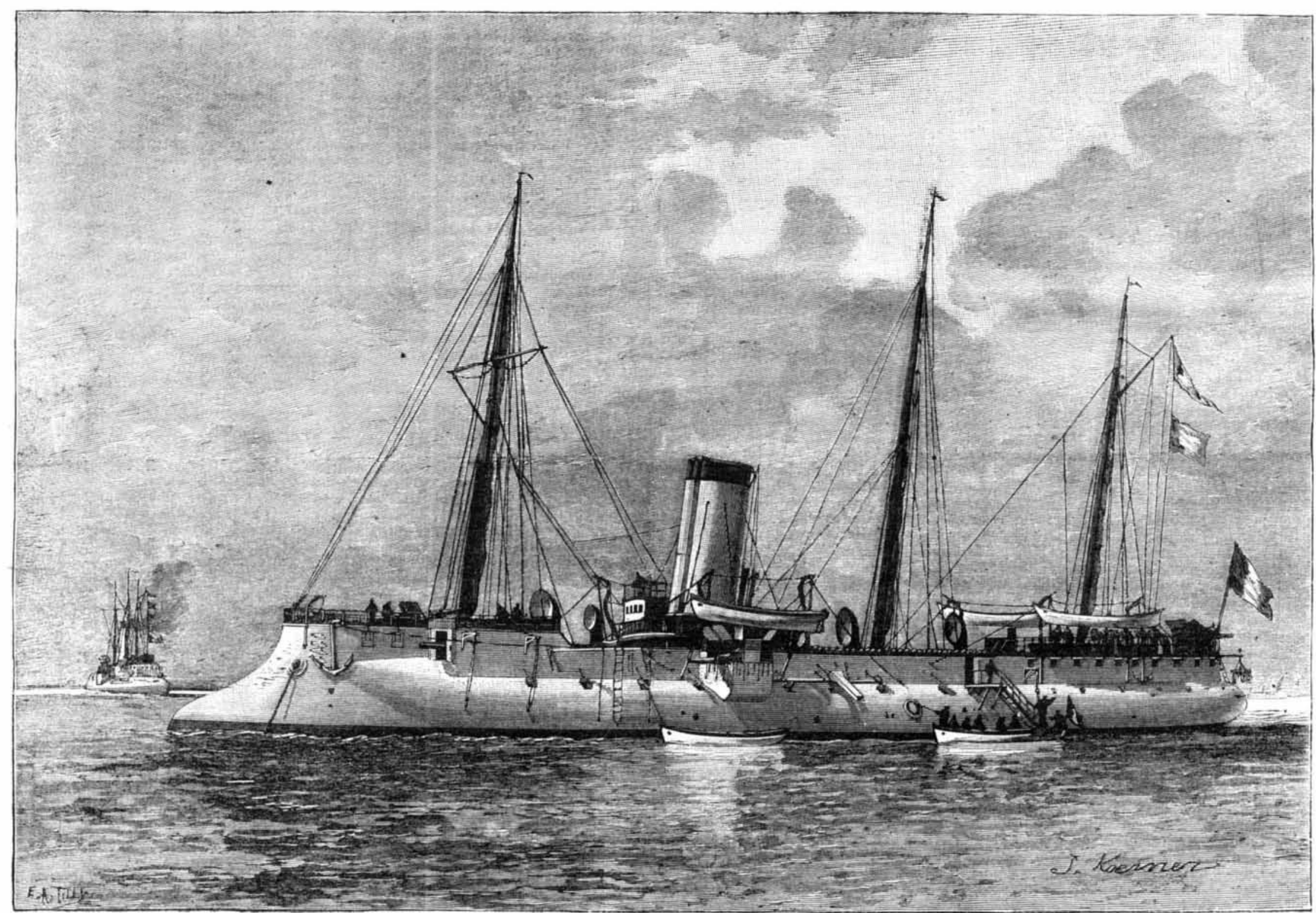

THE FRENCH TORPEDO CRUISER CONDOR.

\begin{tabular}{l|l|l|} 
of steel extending from stem to stern. This deck is & smooth, hard bed, unyielding and with far greater sup- \\
situated a little beneath the float-water line and pro- & porting power than would be required, is always found
\end{tabular} situated a little beneath the float-water line and pro- porting power than would be required, is always found tects the vital parts-engines, boilers, rudder appara- in dry weather. It becomes very compact, so much so tus, etc. Besides, the hull is divided into ten water- that it is impossible to press the point of a walking

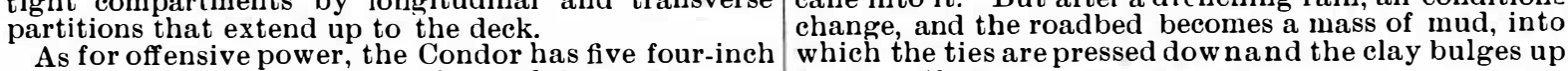
guns, five torpedo tubes, and six revolving guns. The motive apparatus, which is of 3,200 indicated
h. p., consists of two directly connected compound engines. We must add, for the greatest honor of our engineers, The clays vary considerably, however, in their chem-
that the plans of the Condor are the first that were ical constituents, and are affected thereby in the degree made to respond to the programme that we have given to which they absorb moisture. Certain deposits are
above. It is under their inspiration that the Scout known to be compact and hard, with a high supporting type was created in England-a type that made so power, while others are in the condition of a plastic still, it has been found that our Condor is superior, as tic, which renders all clay more or less unstable, when still, it has been found that our Condor is superior, as tic, which renders all clay more or less unstable, when our neighbors. Thus, the English cruiser Cossack property of retaining water once admitted to it, and 18.5 - a fact so much the mile the Condor easily makes first gauges nearly 400 tons more than the second.

To-day, the Condor has been experimented with suf-
ficiently to permit of judging definitely of the services ficiently to permit of judging definitely of the services that she can easily keep up a mean speed of 17 knots. This is a splendid result. The ves
Captain Lormier.-L'Illustration.

Great bell at Cologne Cathedral, presented by the German Emperor in 1876, weighs 60,480 pounds, the clapper alone weighing 1,200 . It was
The stiff blue clay deposits of London are celebrated as much for the numerous failures of the bridge ons to the square foot of foundation, and failed. Blackfriars' Bridge had about 5 tons and appeared
to be stable for many years, but ultimately settled to be stable for many years, but ultimately settled New London Bridge was built in 1831 and founded imposed. Of course, it has settled-in some places as Old Westminster Bridge had probably about $51 / 2$ quare foot upon the clay was at no place greater than tons, and was probably even less than this amount he building showed a certain amount of settlement de of it suddenly third year after being built, one foot or more in a single day, becoming so dangerous that the occupants were compelled to abandon it. The side which had failed was immediately torn down, a new foundation of broader dimension put in, and the wall reconstructed. The load per square foot on the clay
of the new wall is about $1 \frac{1}{2}$ tons, and, as far as the author knows, has remained intact. All along the side of the wall which failed was an open area, which wa was the cause of the clay becoming softer than it otherwise would have clay becoming sof ter than it otheruilding, while showing more or less settlement, yet emained comparatively in good condition. In the city of Cleveland, Ohio, many heavy strucures have been founded upon clay deposits, and one or two notable ones have shown serious settlements. and the foundations of which were described in the Journal of Association of Engineering Societies, the pressure per square foot of foundation on those pier nd abutments which rest directly upon the clay has been limited to from 1 to $1 \cdot 7$ tons. The abutments sesting upon "a mixture of blue sand and clay, with peme water," while the piers, giving a load of but 1 ton per square foot, rest upon a "plastic blue clay of vari- 
EXAMPLES OF FOUNDATIONS ON SOILS.

(IN TONS OF 2,240 POUNDS.)

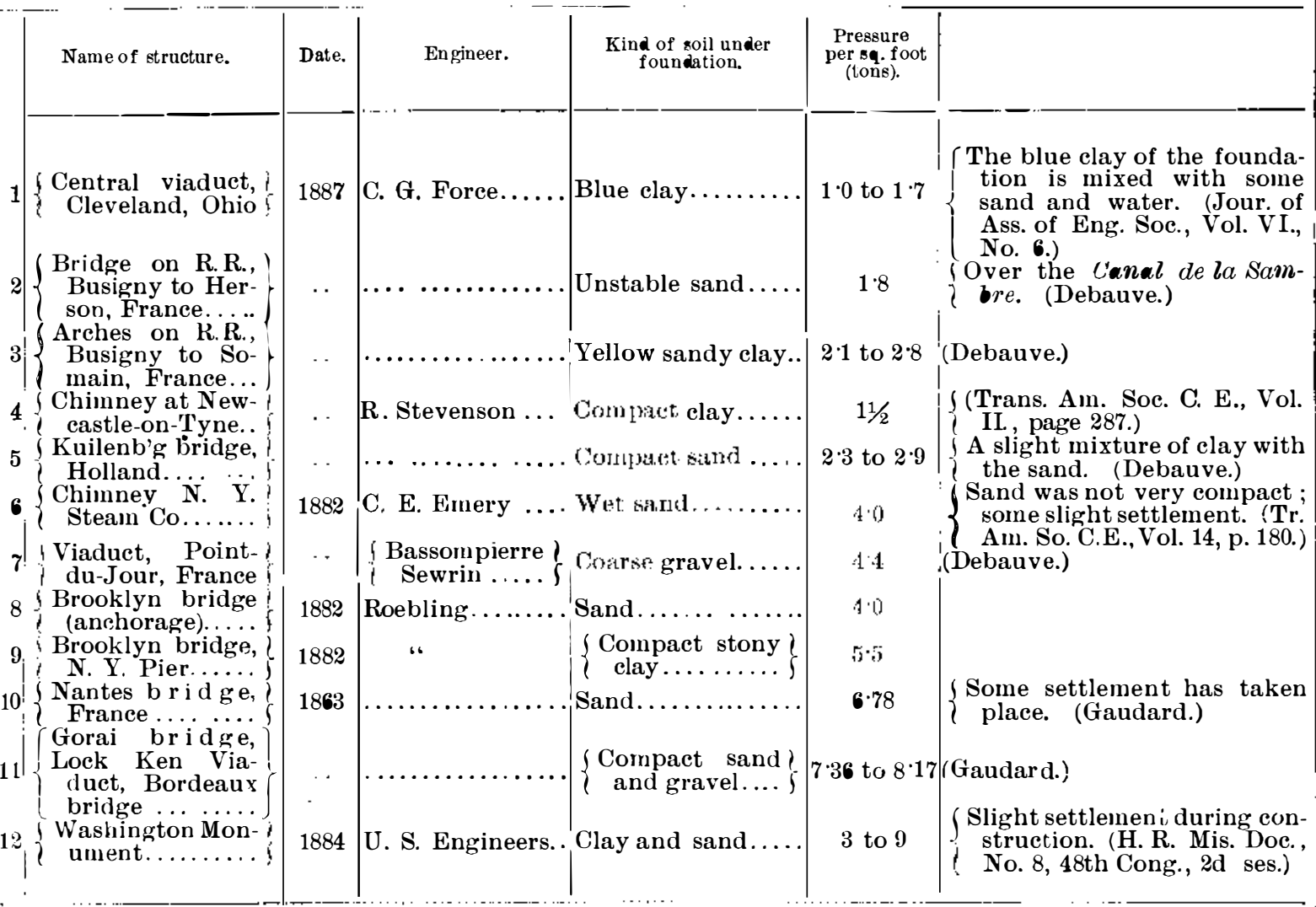

When clay is mixed with other materials, as coarse merly extended to this point. This sand was quite sand and gravel, its supporting power usually largely fine, with pockets of gravel, and containing at a few increases, being greater in proportion as the other ma- places some stone. The sand was thoroughly saturated
terials are in excess, up to the point of forming a con. with water, and would flow when disturbed or under-

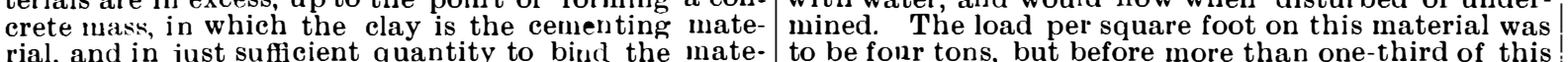
rial, and in just sufficient quantity to bind the mate- to be fonr tons, but before more than one-third of this
rials together. In this condition we of ten find the clay amount was placed upon it, slight settlements occurred in an indurated state and the hardness of the mixture which were not uniform. After the structure was soils are safe for heavy loads, approximating that of the softer rocks.

Brennecke, in his book on foundations, mentions a large chimney with a load of 6 tons per square foot on hard clay. This is an extraordinars example, and we are stated, that it was upon some such hard minixture of clay and gravel as mentioned. At any rate it would be a bad precedert to follow in loading beds of pure clay.
The Washing ton Monument is founded upon a layer of clay and sand. When the shaft was up 150 feet, an
investigation showed that the foundation was entirely investigation showed that the foundation was entirely inadequate upon which to complete the structure-a that such a soil should never be loaded above 10 , pounds per square foot. The foundation was therefore
made heavier and larger, and the shaft successfully
completed with a height of 555 feet. Colonel Casey, the engineer in charge. reports the pressures upon the soil as nowhere exceeding nine tons per square foot, edges. to the old foundations was about two inches, and afterward a further settlement grad ually occurred during construction of two inches more, making a total of four
inches. If the load per square foot on the soil reaches the amount of nine tons, it is the heaviest load upon such a soil which we find any record of, and we think
the doubts expressed by different persons as to the
ultimate stability of the monument entitled to careful consideration.
Supporting Power of Sand. - Foundations on coarse sand and gravel are usially successful, particularly if
free from the action of running water, and structures, free firom the action of running water, and structures,
proportioned in accordance with any ordinary rules of proportioned in accordance with any ordinary rules of
good construction. are hardly likely to have an area of base which will not be sufficient to limit the load per unit to the safe carrying capacity of the soil. Coarse pand deposited in beds has usually a high supporting this, for it also depends somewhat npon how it has
been deposited. On beds of sand made artificially, as is been deposited. On beds of sand made artificially, as is
often done for foundations, the dry sand loosely thrown down does not form a compact mass such as is desirable, and a certain amount of compressibility will exist. it was found that by pounding the sand in thin layers
its density could be increased one-fifth, and that there
still remained about 20 per cent. of voids which could
be notably reduced by simultaneously treating the be notably reduced by simultaneously treating the
sand with water while the stamping down took place. means of hydraulic presses, and the result obtained means of hydraulic presses, and the result obtained
that river sand treated as above would resist up to
pressures of $1,420 \mathrm{lb}$. per square inch.

Water is the chief agent which makes the particles
separate and draws them into the voids of the mass. separate and draws them into the voids of the mass, and is invaluable in all works of embankment in which
solidity is required; but it must also be well drained
off, because if the original amount should remain of off, because if the original amount should remain, of
course the mass of earth would continue in a semi-fluid

Mr. McDonald, in constructing the iron ocean pier at
state. Coney Island,* assumed that the safe load per square foot upon the flanges of the iron disks, which were
sunk into the sand, was five tons. But many of them really support as much as 6.3 tons continually, and are suot, which they appeared to sustain without settle-

The foundation of the large chimney of the New York Steam Companyt was made of concrete resting *'Trans. Am. Sec. C. E., Vol. 8.
† Trans. Am. Soc. C. E., Vol. 14. ause any material damage.
In contrast with the loading of the partly unstable sand of this chimney may be mentioned the loads
which were imposed upon a clean, coarse sand in the which were imposed upon a clean, coarse sand in the
foundations of the Pacific Mills chimney, at Lawrence, ass. Here the sand was inclosed by tight sheet pil-
and only 1.83 tons per square foot placed upon it. The anchorage of the Brooklyn Bridge rests upon and, with a pressure of about 4 tons per square foot. n sand, has a pressure of 6.78 tons per square foot, but The safe somewhat.

The safe loading upon the sandy soil of Berlin is generally taken at about $2 \cdot 3$ tons. Brennecke describes
his sand as being comparatively loose, but likewise entions its having been successfully loaded up to $4 \cdot 1$ Whs per square foot.
When sand is mixed with other materials, such as lay or loam, which have the power of retaining water, ts supporting power grows less, and proportionally
more so as the sand becomes finer and loses its sharp"ess. Of such a nature is the commonly called tween pure sand and pure clay, veiniy a mixture of
them both. Pure clay is composed of alumina, water,
and silica, and in proportion as the silica is absent the and silica, and in proportion as the silica is absent the more water will it hold. This is the material which, when
mixed with the rery fine and rounded grains of sand makes it "quick." Deposits of such are often found,
which through long draining have lost all the water which through long draining have lost all the water
and which appear dry, and loose, and easy to excavate or handle, and generally of a whitish color.
If we could keep such deposits absolutely free from saturation with water, we could truet it with moderate
lods. Its weight is less than either good sand or oads. Its weight is less than either good sand or clay, running from seventy to ninety pounds per cubic At the foundations of the capitol at Albany, Mr. W.
McAlpine describes some of the material as being quicksand without the water. Experiments made in
the soil of this foundation showed that under a weight of two tons per foot no perceptible displacement occurred; and at about five tons the surrounding soil
was forced upward. It was endeavored to place no was forced upward. It was endeavored to place no
more than two tons per foot upon the soil with the completed building, and great pains were taken, by whole area, and inclosing it in a puddled wall, to keep ations have partly failed, and serious cracks have ap pearfil in different parts of the structure. We wish hall make later on, upon judging of the supporting We have not been able to tind any complete accoun of how they were made in this case.
We tind recorded by Debauve a case of founding pon a loose, watery sand, partaking somewhat of the nature of quicksand, in which the load per square
foot was 1.8 tons. The sand is described as being of a sirupy consistency, and after endeavoring to excavate feet in depth, they filled back into this partially excaupon it, and completed the structure. which was a
bridge over the canal of the Sambre â l'Oise. for the bridge over the canal of the Sambre a l'Oise for the
railroad from Busigny to Herson in France. No aftervands and gravel appears to have been of much ser-
vice in many cases. Trautwine records an example of
its succesfuluse vice in many cases. Trautwine records an example of
its successful use in making a foundation over quick.
sand for the brick aqueduct for supplying Boston with sand for

Supporting Power of Soft Soils.-In speaking of soft soils we generally mean those which are referred to as
being compressible, though really this is more or less of This method of treating quicksands with coarser a misnomer, for they are regarded as being the more compressible in proportion to the amount of water
they hold, and yet we know water is practically incompressible. Debauve, in his excellent work on founda-
tions, makesthis distinction clear, and classes such soils
as "mobile." movable, which in itself is a true definiThe their characteristice

of many rivers gives us the best general in most others, the soft soils are usually found at the lower end of rivers flowing through valleys of considerable width, and emptying into the sea or large the larger body of water, causing the detritus held in suspension to be deposited in beds of greater or less
thickness; or by overflowing their banks and spread ing far and wide throughout the valley the waters lose sufficient velocity to carry the suspended matter further. An example of the greatest magnitude, of such formation, is seen in the country adjacent to the lower
Mississippi, and much of the State of Louisiana has been formed in this way. Here is to be found the "prairie tremblante," or trembling prairie--vast soil, overlaid by a mass of decayed vegetable matter, and which, tied together by rootlets, forms a more solid, but trembling, crust.
It is impossible, of course, to solidly found anything upon such soil ; but rather must any such attempt be
regarded as a problem of flotation in a muddy liquid. Yet we are often called upon to construct railroads,
bridges and buildings in soil but a trifle more solid and homogeneous.

The supporting power of all soils is of course depend ent more or less upon the depth at which the founda-
tion is made, and in the alluvial soils such as we are now considering this is of more importance than in paper to enter into this matter more fully and in ou remarks we have treated upon the supporting power of y depth.

The softer clays really belong to and should be which we are now alluding.

The actual supporting power of such soils can hardly e given in figures which ean be of much real value 作 all the larger buildings and structures, which have many cases the directly upon the alluvial soil, and in my cases the load per square foot is much less than
ton. From some experiments made in India in alluton. From some experiments made in India in allu-
while sir the safe load pert square foot is given as 1 ton
wharles Fox finds it to be only 1,680 pounds or the soil which he tested.

Experiments to determine the weight which can be safely placed upon soft soils have of ten been made, but
are not generally of much value, unless the area of soil ef about the same extent as the base of the oundation to be placed upon it. This was very clearly ments made in the soft alluvial soil of the valleys of
ment ilane and l'Oust.

A number of small piers of masonry, 6.56 feet square. were built at different points, and made of such a pat of the large embankment which it was the in tention to afterward construct. It was supposed that these
piers would settle deep into the mud, but they really piers would settle deep into the mu, but they really xerting a pressure per square centimeter of only one alf that of the piers, showed in all cases very much greater settlements.
The explanation was simple : if a small pier, with a quare base, is pressed down into the soft soil, the frictional resistance against the sides of the compressed ground is proportional to the length of these sides:
while a square pier of, say, double the width would experience a frictional resistance just twice that of the
irst pier. In other words, this resistance is directly prst pier. In other words, this resistance is directly
proportionate to the length of the perimeters of the proportionate to the length of the perimeters of the
bases. But the area of the base of the second pier is our times that of the first, hence we see that, with an would have much more resistance to overcome than a arge one, and that one would be at fault to take as a correct measurement of the supporting power of the area. Experiments upon the soil in New Orleans, made in 1851 and 1852, and which are recorded in Van Nos trand's Magazine, Vol. 27, showed analogous results.
Stated then as a proposition : The supporting power of soft soils is greater in proportion as the ioaded urea ot support as much weight, per unit of surface, as This principle is most important, and should not be pplicable to the supporting power of bearing It is nd hence any formula for the same which does no make a distinction due to different sectional areas of the of Engineering Societies.

\section{MANUFACTURE OF GLASS BOTTLES IN} GERMANY.

By D. J. Partello, U. S. Consul, Dusseldorf. Within the consular district and about five miles rom the city of Dusseldorf, in the valley of the Rhine, bottle manufactory of Ferd. Heye, of Gerresheim, claimed to be the largest establishment of the kind in the
world owned and operated by one individual. Its convenience for obtaining supplies is second to none ernment, pass the establishment, one line leading diret into the yard.
The suall German town of Gerresheim, containing The snall German town of Gerresheim, containing
bout 3,000 inhabitants, inmediately adjoinsthe works the two being inseparable on account of the mutual
interests involved, and it is properly said here that

* Clemann's Railroad Engineer's Practice. 